\title{
Interactive comment on "Repeated
} electromagnetic induction measurements for mapping soil moisture at the field scale: validation with data from a wireless soil moisture monitoring network" by E. Martini et al.

\section{N. Romano (Editor) \\ nunzio.romano@unina.it}

Received and published: 29 April 2016

Dear Authors, Within the spirit of the D-phase of HESS, I am writing to invite you to start providing preliminary responses to the comments received so far.

Interactive comment on Hydrol. Earth Syst. Sci. Discuss., doi:10.5194/hess-2016-93, 2016. 